\title{
Does physical education foster skill acquisition in novices from childhood to adolescence?
}

\author{
Michael Gromeier \\ Neurocognition and Action - Biomechanics"- Research Group, \\ Bielefeld University, Bielefeld, Germany \\ Thomas Schack \\ Neurocognition and Action - Biomechanics"- Research Group \\ Center of Excellence "Cognitive Interaction Technology" (CITEC), \\ Research Institute for Cognition and Robotics (CoR-Lab), \\ Bielefeld University, Bielefeld, Germany \\ Dirk Koester \\ Neurocognition and Action - Biomechanics"- Research Group \\ Center of Excellence "Cognitive Interaction Technology" (CITEC), \\ Bielefeld University, Bielefeld, Germany
}

\begin{abstract}
The goal of this study was to examine age and gender-related differences in quantitative and qualitative throwing performances of novices across a lifespan six to 16 years of age. Quantitative and qualitative throwing performances of 110 participants were evaluated in a controlled setting. The overall throwing movement was also sub divided into five essential movement characteristics: trunk, forearm, humerus, stepping, and backswing actions (Halverson \& Roberton, 1984).The participants had to throw as hard and accurate as possible aiming a target on the wall. Each trial was videotaped for qualitative data analysis which has been conducted by using a modified component approach. The present findings show that across the three age bands, novices stagnated on a low level of movement development. Also, gender differences in the development of the throwing movement characteristics were found for the age band childhood and in some features gender differences were sustained throughout the examined age bands until adolescence. Within the novices, higher performance values in favour of male were found during childhood for trunk, forearm, and backswing actions, and in the quantitative performance-measure. Within the pubescence, gender differences existed only for trunk action and within the adolescence only for backswing action. There were no progress in throwing movement characteristics between the various levels of motor development. Thus, no improvement of the throwing movement quality and accuracy (quantity) could be recognised, which is calling for improvements in physical education. Compared with athletes in the same age, in contrast a study by Gromeier, Koester, and Schack (2017) show that with increasing age, qualitative performance of male and female athletes improves and furthermore it can be seen that male and female athletes demonstrated similar movement patterns in the main function phase. That raises questions concerns issue of physical education.
\end{abstract}

Keywords: complex motor skill, component approach, handball, motor development, children,adolescence

During learning of complex motor skills, children, youth, and adults are repeatedly confronted with excessive demands coordination (Hamilton \& Tate, 2002). With regard to the age, gender, and expertise what contributes to considerable differences in performance in the throwing 
behaviour. High level sport-specific motor skills are important to achieve the goals in individual or team sports (Schack \& Bar-Eli, 2007, S. 62). Given the importance of throwing movements in many disciplines, for example handball, baseball, and javelin, we aimed to better understand the changes in performance during development.

Earlier assessment approaches like Total Body Approach (Wild, 1938) also called Structural Approach implied that all throwers have the same movement execution in a given developing stage (Langendorfer \& Roberton, 2002). This approach did not detect changes in the throwing pattern of single body parts. Thus, it is difficult to give statements about the development of components of the throwing movement and also to answer the question of how the development of one stage to another takes place (Langendorfer \& Roberton, 2002). Roberton (1977) designed a new approach to analyze throwing movements. A variation leads to the Component Approach of Halverson and Roberton (1984), which is currently the most commonly used motor analysis approach (Goodway \& Lorson, 2008; Ehl, Langendorfer \& Roberton, 2005; Hamilton \& Tate, 2002; Barrett \& Burton, 2002; Langendorfer \& Roberton, 2002; and Roberton \& Konczak, 2001). Accordingly, the full body movement is separated into functionally relevant components (see Table 1), which allow statements about the development of particular components. Therefore, it is possible to classify the development of motor learning process. It provides "a useful framework to describe the wide variety of possible configurations of the body components, and permits to examine the factors influencing the movement system including the influence of otherbody components on the throwing movement." (Lorson, 2003, p. 41).

Table 1

\section{Component Approach}

The five components according to the modified component approach (Halverson \& Roberton, 1984) and the main developmentally characteristic levels ( $\mathrm{T}=$ Trunk; $\mathrm{H}=$ Humerus; $\mathrm{F}=$ Forearm; S = Stepping; B = Backswing).Grades from worst (0) to optimal (3) movements.

\begin{tabular}{|c|c|c|c|c|c|}
\hline Component & Grade & Characteristic & Component & Grade & Characteristic \\
\hline \multirow{4}{*}{ Trunk } & T0 & $\begin{array}{l}\text { Varying movement in trunk } \\
\text { action }\end{array}$ & \multirow{4}{*}{ Stepping } & S0 & $\begin{array}{l}\text { Varying movement in } \\
\text { stepping }\end{array}$ \\
\hline & $\mathrm{T} 1$ & $\begin{array}{l}\text { No trunk action or forward- } \\
\text { flexion }\end{array}$ & & S1 & No step \\
\hline & $\mathrm{T} 2$ & $\begin{array}{l}\text { Upper trunk rotation or block } \\
\text { rotation }\end{array}$ & & S2 & Ipsilateral step \\
\hline & T3 & Differentiated rotation & & S3 & Contralateral step \\
\hline \multirow{4}{*}{ Humerus } & HO & $\begin{array}{l}\text { Varying movement in } \\
\text { humerus action }\end{array}$ & \multirow{4}{*}{ Backswing } & B0 & $\begin{array}{l}\text { Varying movement in } \\
\text { backswing }\end{array}$ \\
\hline & H1 & Humerus oblique & & B1 & $\begin{array}{l}\text { Backswing behind or beside } \\
\text { the head }\end{array}$ \\
\hline & $\mathrm{H} 2$ & $\begin{array}{l}\text { Humerus aligned but } \\
\text { indipendent }\end{array}$ & & B2 & $\begin{array}{l}\text { Backswing behind or beside } \\
\text { the head Insufficient } \\
\text { backward extension }\end{array}$ \\
\hline & H3 & Humerus lags & & B3 & $\begin{array}{l}\text { Nearly complete backward } \\
\text { extension }\end{array}$ \\
\hline \multirow{4}{*}{ Forearm } & F0 & $\begin{array}{l}\text { Varying movement in } \\
\text { forearm action }\end{array}$ & & & \\
\hline & F1 & No forearm lag & & & \\
\hline & F2 & Forearm lag & & & \\
\hline & F3 & Delayed forearm lag & & & \\
\hline
\end{tabular}

Note. Modified Component Approach by Halverson \& Roberton, 1984, Developing Children Their Changing Movement, p. 103ff. Copyright 1984 by Philadelphia: Lea \& Febiger.

The throwing movement develops over a very large part of the lifespan. Already in toddlerhood, first throwing movements and spinning movements can be observed. Due to 
parental and physical education in childhood, the qualitative skills develop (Meinel \& Schnabel, 1998). Within early childhood, findings have pointed towards gender differences in qualitative characteristics of throwing movement, specifically in stepping and trunk actions (Thomas \& French, 1985; Nelson, Thomas, \& Nelson, 1991; and Winter, 1987). At the age of ten to twelve years, in the phase of "best motor learning" (Meinel \& Schnabel, 1998) motor skills developed further and differences in the throwing behaviour within and between boys and girls arise.

Within pubescense, Goodway and Lorson (2008) found significant gender differences in stepping, trunk, and forearm actions. Due to the accelerated growth in the early adolescence, difficulties in the complex motor skills are visible and differences in throwing performance increase. Lorson, Stoddon, Langendorfer, and Goodway (2013) examined age and gender differences in throwing performance of middle adolescents until adulthood. They analyzed the throwing pattern for stepping, humerus, forearm, and trunk actions and found gender differences within adolescents and young-adults in stepping, trunk, and forearm actions. Lorson et al. (2013) reported significant differences within the young adults for all analyzed components. Comparable performances were demonstrated in the throwing pattern between female and male adults. The main developmental slowing for females occurred in movement component of stepping, trunk and forearm actions. For example, female children and youth throw out of a parallel stepping or a small stepping. Instead of a differentiated trunk rotation, they often use a block rotation, and during the throwing phase the forearm is under shoulder high. Male children usually demonstrate the same developmental patterns, but they seem to be four to five years ahead of females (Halverson, Roberton, \& Langendorfer, 1982). Within the same age, male use more a full body movement and lateral stepping (Winter, 1987).

These studies point to gender related differences in the qualitative throwing movement characteristics in favour of male novices (Lorson et al., 2013; Goodway \& Lorson, 2008; Nelson, Thomas, \& Nelson, 1991; Winter, 1987; and Thomas \& French, 1985). Also, age related differences have been reported (Lorson et al., 2013; Halverson et al., 1982; Winter, 1987). The differences in the qualitative characteristic of throwing movements cause gender differences in the throwing accuracy in favour of male (Ahnert, 2005; Gaschler, 1998; Geese, 1997; Keogh, 1969; Thomas \& French, 1985; and Vogt, 1978) and the throwing velocity or hardness (Geese, 1997; Keogh, 1969; Morris, Williams, Atwater, \& Wilmore, 1982; Roberton\&Konczak, 2001; and Thomas \& French, 1985). It is remaining difficult to compensate such gender difference which leads to an improvement in qualitative characteristic of throwing movements. "The attempt to influence gender-specific differences by training or instructions positive, has so far led to hardly any successes." (Thomas, Michael,\& Gallagher, 1994, p. 65).

With a view to the essential components of the throwing movement, the first goal of the present study was to identify the basic problems in the development of throwing movement of novices and to analyze typical throwing patterns in three different levels in motor ontogenesis, which may provide insights about the influence of instruction and practise in school settings. The second goal of this study was to analyze the influence of age on the qualitative and quantitative performance of the throwing movement within.

Based on previous studies (Lorson et al., 2013; Goodway \& Lorson, 2008; Meinel \& Schnabel, 1998; and Halverson et al., 1982), it was hypothesized that within novices the performance improves with increasing age. Furthermore, it was hypothesized that from a certain point of age the qualitative and quantitative performances of the overhead throwing movement differs between male and female novices in favour of males, and that these gender differences widen with increasing age (Goodway \& Lorson, 2008). 
Third goal of this study was to compare present findings to throwing performances of young athletes and their skill acquisitions in throwing, in order to find out how far does school education gets and weather it is possible to achieve similar skill acquisitions as in club sport or whether it is necessary to complete a club-oriented training for a satisfying learning effect?

Accordingly the question is: How does physical education foster skill acquisition in novices during childhood and adolescence compared to athletes of sport clubs in the same age range? Therefore we point out comparison refer to athletes (Gromeier et al., 2017), which implies that on the one hand the method, which was used works and on the other hand it is sensitive enough.

Gromeier et al., 2017 analyzed aspiring athletes, competitive in the sport handball, which were also invited to throw three times from three different distances, while aiming at a target placed at shoulder height. As in the present study the component approach of Halverson and Roberton (1984) was used to analyze the quality of movement. The throwing accuracy was noted and used to evaluate the quantitative performance of the throwing movement (Gromeier et al., 2017).

Comparisons of separate movement components based on results of athletes show that not all components are affected similarly (Gromeier et al., 2017).

The component approach yielded higher scores for male than for female participants. Introspection shows that differences in the qualitative throwing performance were seen in specific components of action. Male and female athletes demonstrated similar movement patterns in humerus and forearm actions, but differed in trunk, stepping, and backswing actions (Gromeier et al., 2017). And as expected, with increasing age qualitative and quantitative performance of male and female athletes improved. These results suggest that there are gender-specific differences in qualitative throwing performance, but not necessarily in quantitative throwing performance (Gromeier et al., 2017).

\section{Participants}

\section{METHOD}

Overall 110 participants $\left(\mathrm{M}_{\mathrm{age}}=10.76\right.$ years, $\left.\mathrm{SD}_{\mathrm{age}}=2.702\right), 52$ females and 58 males were grouped into three different age bands consistent with the level of development in motor ontogenesis (Meinel \& Schnabel, 1998, p. 240): childhood (age of females 7 -12, age of males 7 - 13), pubescence, (age of females 12 - 14; age of males 13 -15), adolescence (age of females $14-17$, age of males $15-18$, and early adulthood (age of males and females 17/18 - 20). The novices were recruited from an ordinary elementary and comprehensive school. They had no experience in sports such as handball, tennis, and athletics, neither club sports nor leisure group.

The reference group consisted of eight experts ( $\mathrm{M}_{\mathrm{age}}=18$ years, $\left.\mathrm{SD}_{\mathrm{age}}=0\right)$, four female and four male. With a questionnaire and an information letter all parents gave an informed consent. Throughout the testing all participants were healthy and in good conditions.

\section{Task and procedure}

This cross-sectional study has been performed in accordance with the ethical standards of the Helsinki Declaration of 1975. After a general and a purposeful warm up of about 15 minutes, the participants were individually tested. With the instruction "throw as hard and accurate as possible" throwing accuracy and throwing velocity was combined in one task. They had thrown out of a 2.5 to $2.5 \mathrm{~m}$ tall corridor towards a marked square target $(75 \mathrm{x} 75 \mathrm{~cm}$ in size) on 
the wall. This target was placed at shoulder height. They selected a ball and had the choice between different ball sizes, which was in accordance to the quality standard of the International Handball Federation (size $00 ; 0 ; 1 ; 2$; and 3 ) and a tennis ball. The participants should be able to hold the selected ball safely with one hand. All participants completed nine trials, three trials from each distance. The distances have been set according to, two, four, and six times of their body height (see Figure 1).

\section{Data collection}

In a controlled setting the trials were recorded for the qualitative movement analysis using a Sony HDR-CX410VE wide angle lens camera with high speed 1/10000 shutter. The Camera was placed in a 90 degree angles side view of the throwing arm side, at a distance of $5 \mathrm{~m}$.

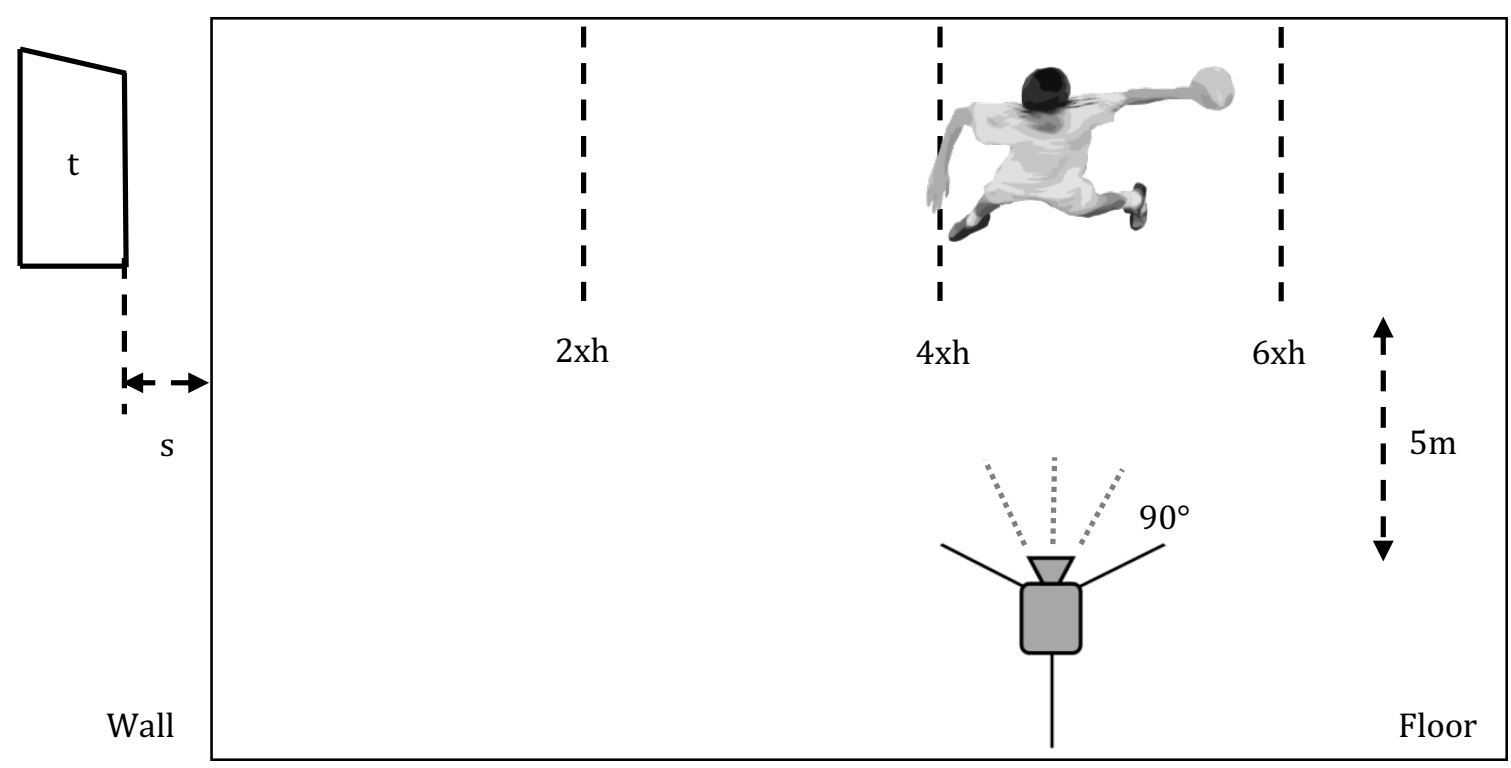

Figure 1 Drawing of the test setup of motor skills examination from bird's-eye view. (h=body height, target area (t) $75 \mathrm{~cm} \times 75 \mathrm{~cm}$ in shoulder height (s), camera in 90 degree angles in a distance of $5 \mathrm{~m}$ to the participant)

To determine the quantitative performance any attempt which hit the marked square target on the wall or which touched the mark was counted as a successful hit. By proving the reliability for the results from the three different distances, a doubtful internal consistency $(\alpha=.657)$ was indicated and only a less positive discriminatory power revealed for the first distance. Because of this item-scale-statistic the item "hits from two times of their body height" was excluded from the data analysis.

Using a modified assessment of Robertson's component approach (Halverson \& Roberton, 1984; see Table 1) the qualitative characteristics of the throwing movement was examined. Therefore, three experts (two handball coaches with an A- and B-license and one former international handball-player) have made a valuation of the five essential component actions for each participant. Using Cronbach's alpha, the authors measured the internal consistency of these three ratings $(\alpha=.782 ; \alpha=.795$, and $\alpha=.746)$. For each of the five component actions: trunk, forearm, humerus, stepping, and backswing, there were three expert ratings. Finally from these three ratings the qualitative performance was calculated. Means (M) and standard derivation (SD) are reported in Table 2. To clarify the influence of variables an analysis of variance (ANOVA) with an adjusted alpha level of .05 was used. 


\section{Data analysis}

In this study, a $3 \times 2$ age (childhood, pubescence, and adolescence) and gender (male and female) one-way analysis of variance (ANOVA) and a significance level of .05 was used to identify effects of age, effects of gender, and interaction effects in quantitative performance of the throwing movement. For post hoc analysis, $t$-tests for independent samples were conducted. A post hoc test (Bonferroni Holm correction) and an adjusted significance level to .017 ( $p=.05 /$ three tests) was employed to locate significant differences in interaction effects (Holm, 1979).

Effects of age and effects of gender in qualitative performance were evaluated using an ANOVA and a significance level of .05; $3 \times 2$ age (childhood, pubescence, and adolescence) and gender (male and female). Furthermore, a 3 x 2 ANOVA was used to assess effects of age and effects of gender for each component separately. Potential interaction effects were follow-up with ttests. A Bonferroni Holm correction and an adjusted level of significance to .017 were used to locate significant differences.

\section{RESULTS}

A summary of means and standard deviation of the qualitative characteristics for all components (trunk, forearm, humerus, stepping, and backswing actions), total qualitative performance, and quantitative performance of male and female novices and the reference group is given in Table 2 . 
Table 2

Variable means and standard deviations of qualitative performance of novices and reference group tracked cross-sectional

\begin{tabular}{ccccc}
\hline \multirow{2}{*}{ Variable } & \multicolumn{3}{c}{ Novices } \\
\cline { 2 - 4 } & $\begin{array}{c}\text { Female } \\
\text { Performance }\end{array}$ & SD & Male & Serformance \\
\hline
\end{tabular}

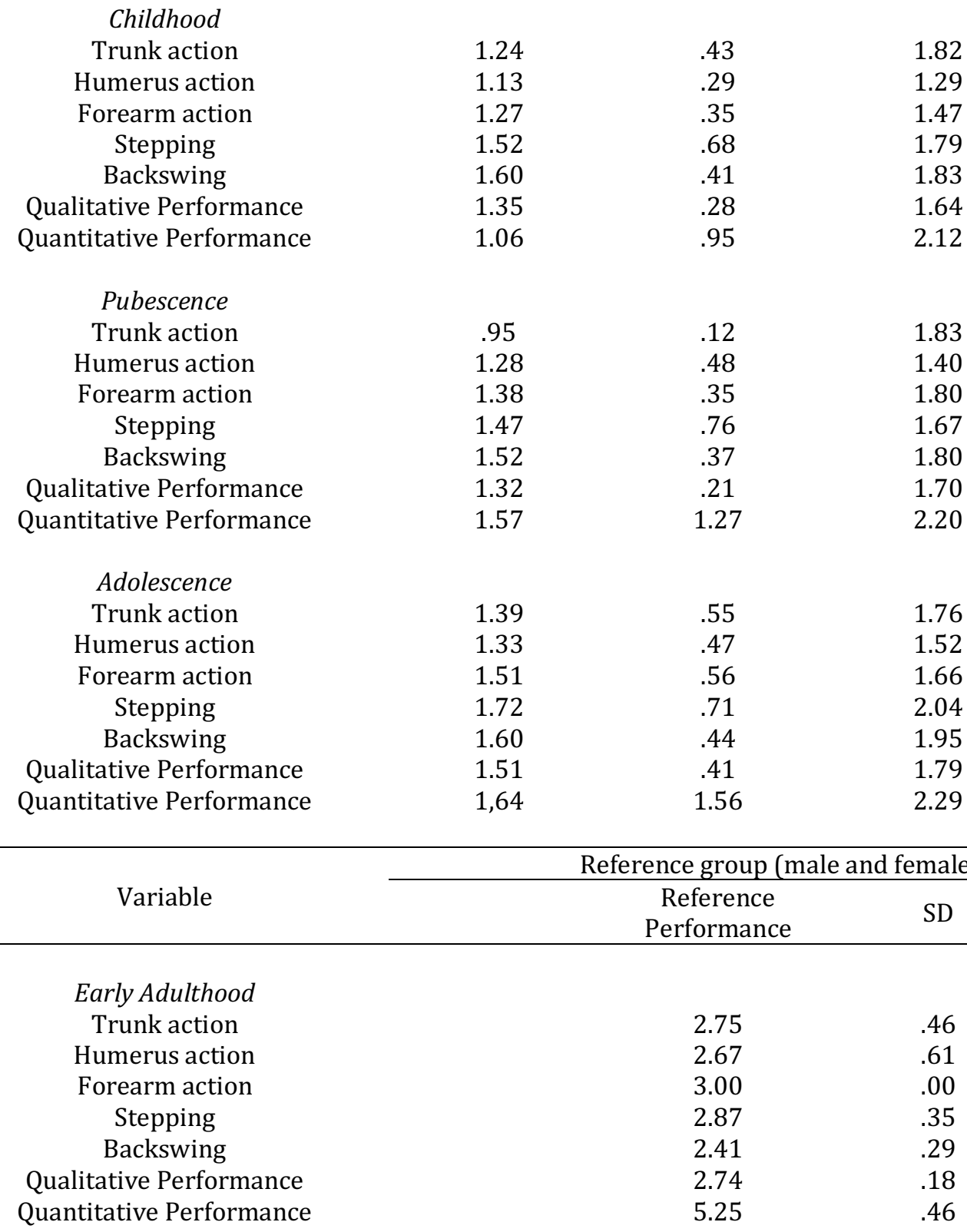

Note. Variable means and standard derivation for all components and quantitative performance within novices and reference group.

ANOVA's were conducted to examine the effect of age and the effect of gender of the total qualitative performance, qualitative performance of single component actions, and quantitative performance. Interaction effects between gender and age were also determined by using an ANOVA procedure. In addition to present results, results from athletes for the same age bands (Gromeier et al., 2017) were added for case of comparison (grey solid and dashed lines, cf. discussion section, p. 23). 


\section{Qualitative movement characteristics}

Qualitative characteristics

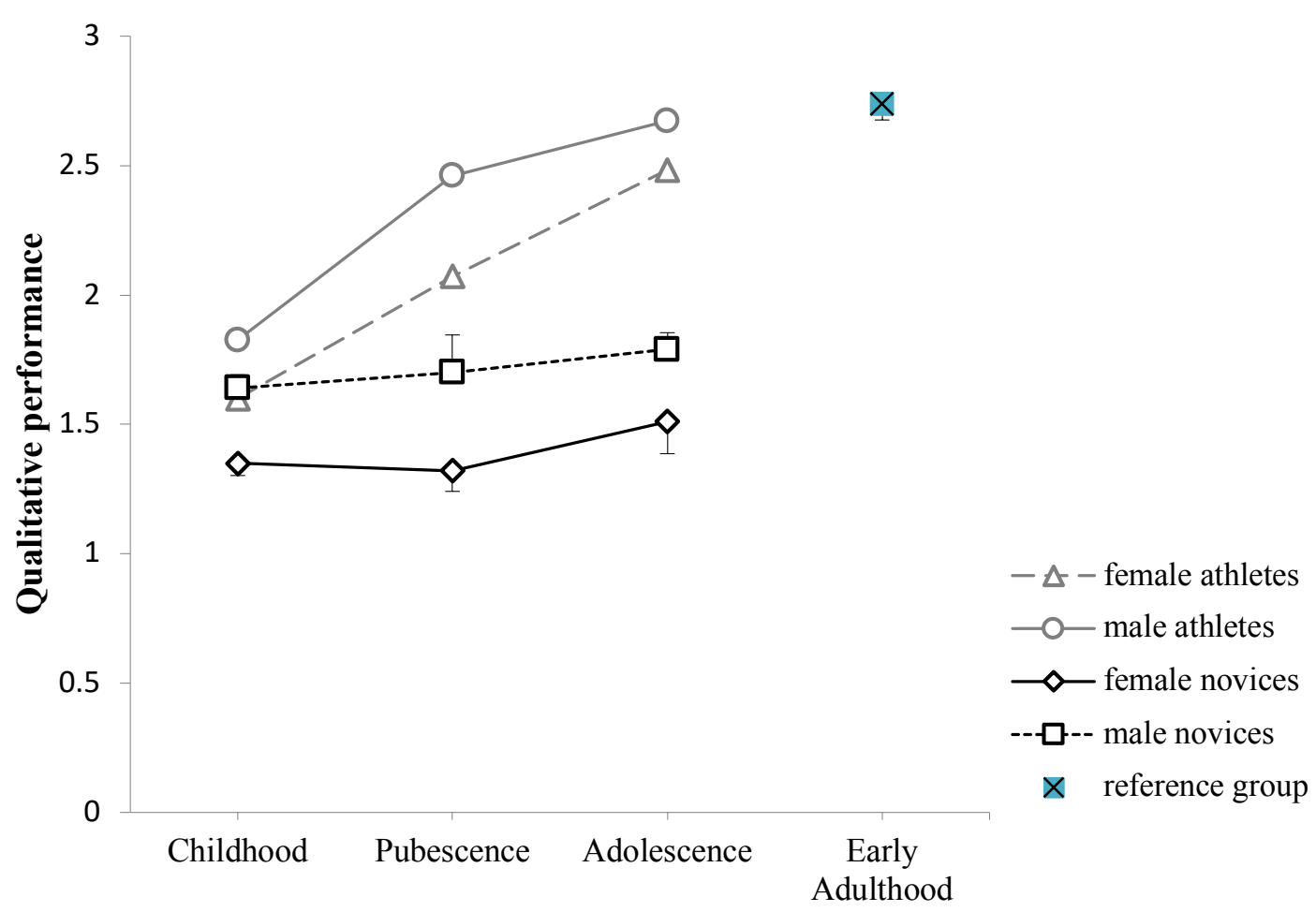

Level of development in motor ontogenese

Figure 2 Changes of the qualitative performance for all components ( $\min .0$ - max. 3) for male and female athletes (Gromeier et al., 2017) and male and female novices as a function of age (childhood, pubescence, adolescence, and early adulthood). Error bars represent standard error. Note: Grey symbols and lines represent data from comparable group here and in all subsequent figures.

The ANOVA with the factors age (3) and gender (2) for total qualitative performance showed a significant effect of gender on qualitative performance of throwing movement, $F(1,104)=$ $15.181, p<.001$. The analysis yielded no significant effect of age on qualitative performance, $F(2,104)=1.446, p=.240$. The interaction effect was not significant, $F(2,104)=.132, p=.876$.

Planned comparisons were performed on separate age bands with Bonferroni Holm correction and an adjusted level of significance $(p=.017)$ to follow-up the main effect of gender. T-tests showed a significant effect of gender on qualitative performance within the childhood, $t(73)=-$ $3.938, p<.001$. 


\section{Quantitative movement characteristics}

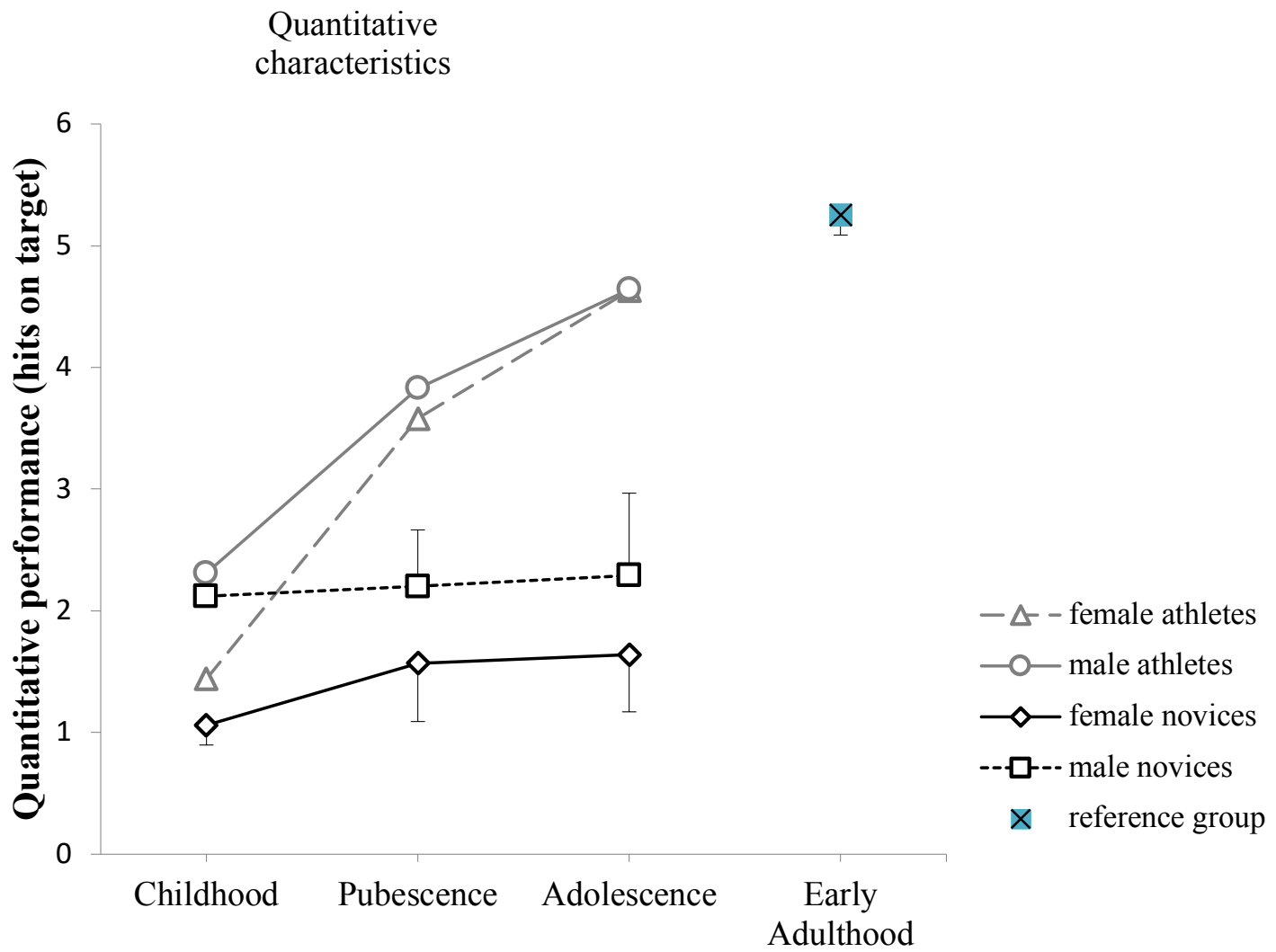

Level of development in motor ontogenese

Figure 3 Changes of the quantitative performance for all components ( $\min .0$ - max. 3 ) for male and female athletes (Gromeier et al., 2017) and male and female novices as a function of age (childhood, pubescence, adolescence, and early adulthood). The quantitative performance was calculated by hits on target or which touched the mark of the target (cf. method section). Standard deviation marked by the error bars.

Figure 3 shows the outcome of the quantitative performance of male and female novices and the reference group. To compare the effect of gender and effect of age on quantitative performance an ANOVA procedure was used. The statistical analysis showed no significant effect of age, $F(2,104)=.777, p=.462$. There is a significant effect of gender, $F(1,194)=6.121, p$ $=.015$. The interaction effect between age and gender was not significant, $F(2,104)=.308, p=$ .735 .

To compare the effects of gender, age and the interaction effect on the qualitative performance of single movement characteristics, following analyzes carried out by means of the ANOVA procedure. To follow-up the main effect of gender, separate t-tests were performed (using Bonferroni Holm correction). T-tests showed a significant effect of gender on quantitative performance within childhood, $t(71.348)=-3.996, p<.001$. 


\section{Changes in the movement of trunk action}

Qualitative characteristics in trunk action

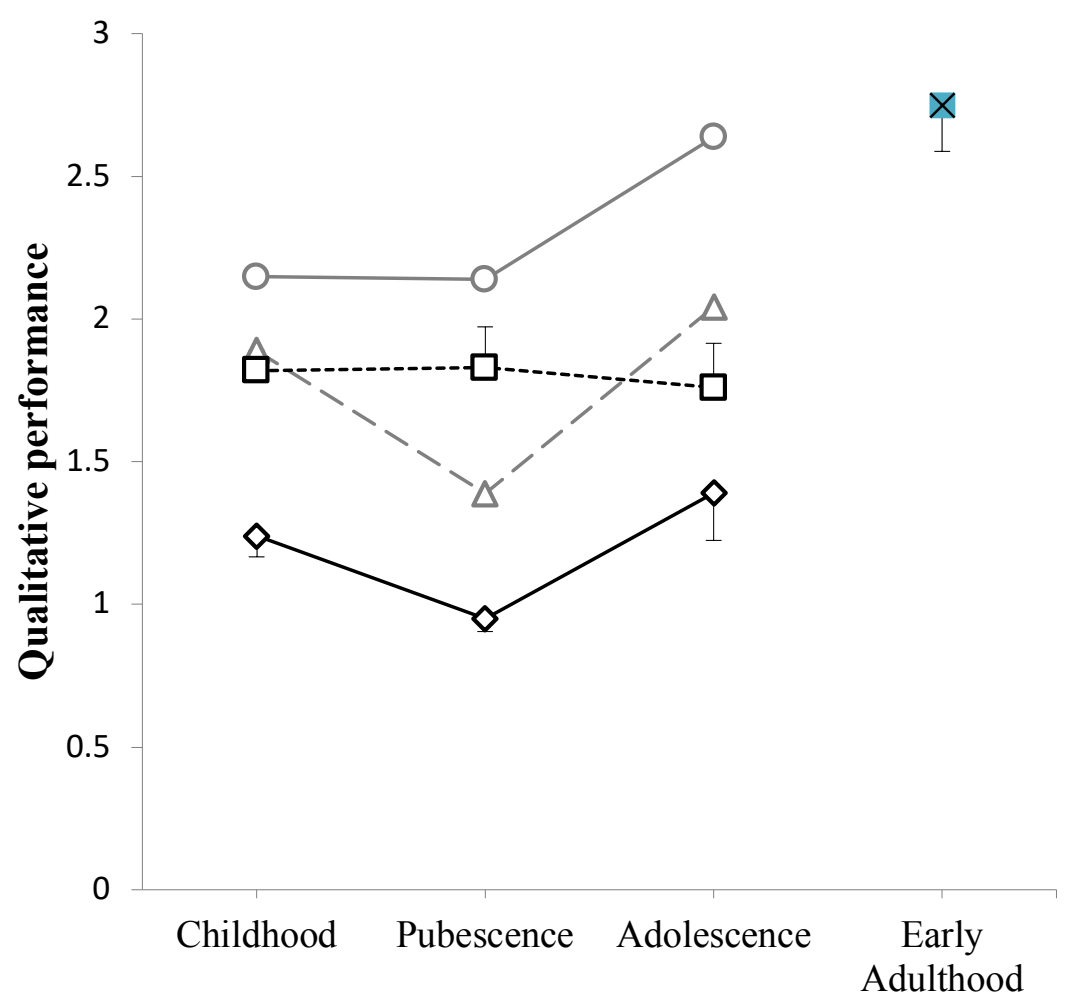

$-\triangle-$ female athletes

- - - male athletes

$\checkmark$ female novices

-- $\square$--- male novices

$x$ reference group

\section{Level of development in motor ontogenese}

Figure 4 Changes of the qualitative performance for trunk action (min. 0 - max. 3) for male and female athletes (Gromeier et al., 2017) and male and female novices as a function of age (childhood, pubescence, adolescence, and early adulthood). The qualitative performance was in a range of .0 to 3.0 and was calculated as the mean of three independent expert ratings (cf. method section). Standard deviation marked by the error bars.

Figure 4 shows changes in the quality of trunk action for male and female novices. The main effect of age was not significant, $F(2,104)=.872, p=.421$. However the main effect of gender was significant, $F(1,104)=32.002, p<.001$. The interaction effect of age and gender on trunk action was not significant, $F(2,104)=1.413, p=.248$. 


\section{Changes in the movement of humerus}

Qualitative characteristics in humerus action

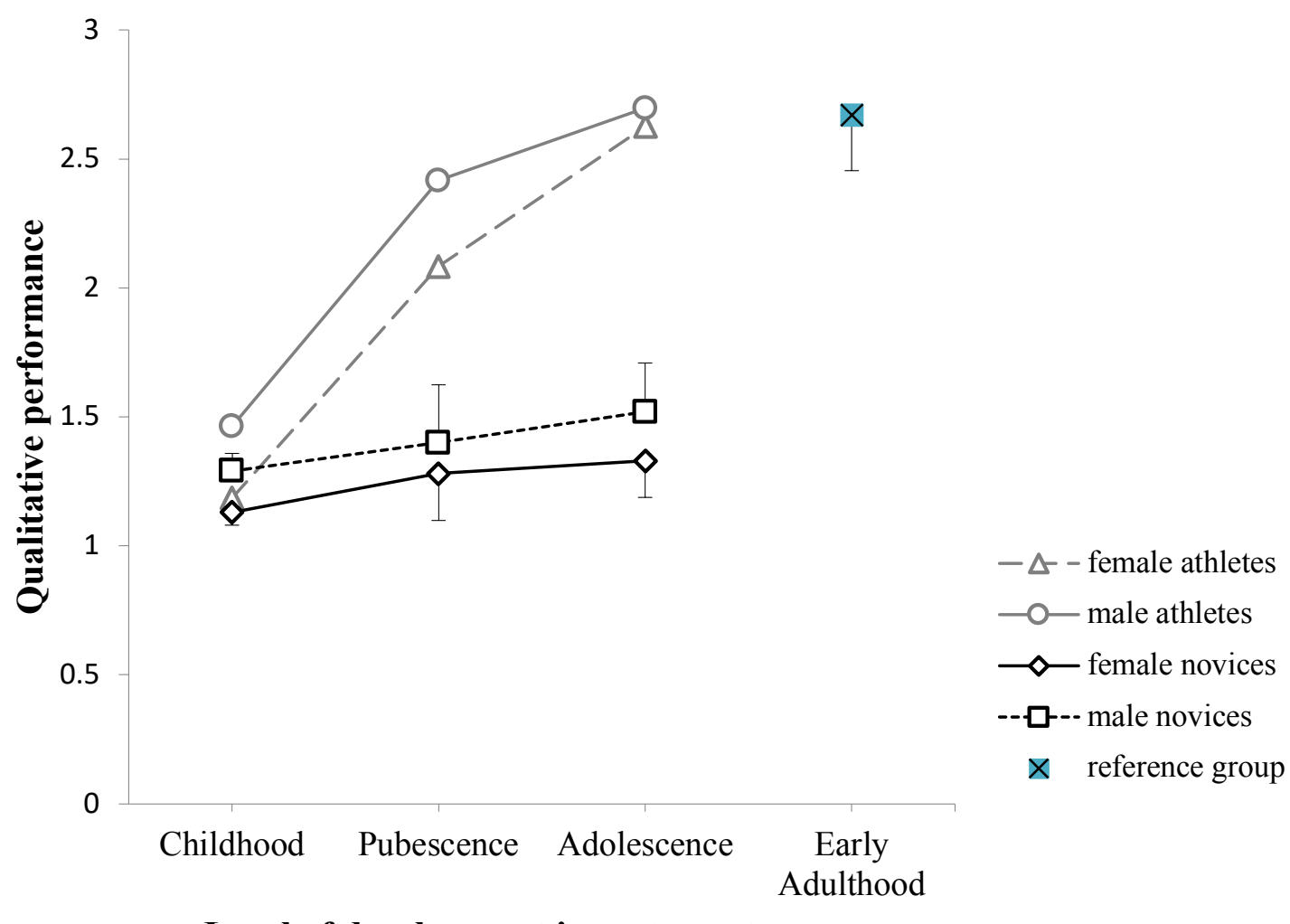

Level of development in motor ontogenese

Figure 5 Changes of the qualitative performance for humerus action (min. 0 - max. 3) for male and female athletes (Gromeier et al., 2017) and male and female novices as a function of age (childhood, pubescence, adolescence, and early adulthood). The qualitative performance was in a range of .0 to 3.0 and was calculated as the mean of three independent expert ratings (cf. method section).Standard deviation marked by the error bars.

Figure 5 shows changes in the quality of humerus action. The main effect of age was not significant, $F(2,104)=1.860, p=.161$. As well as the main effect of age the effect of gender was not significant, $F(1,104)=2.001, p=.160$. The analysis showed no significant interaction effect between age and gender on humerus action, $F(2,104)=.031, p=.970$. 


\section{Changes in the movement of forearm}

Qualitative characteristics in forearm action

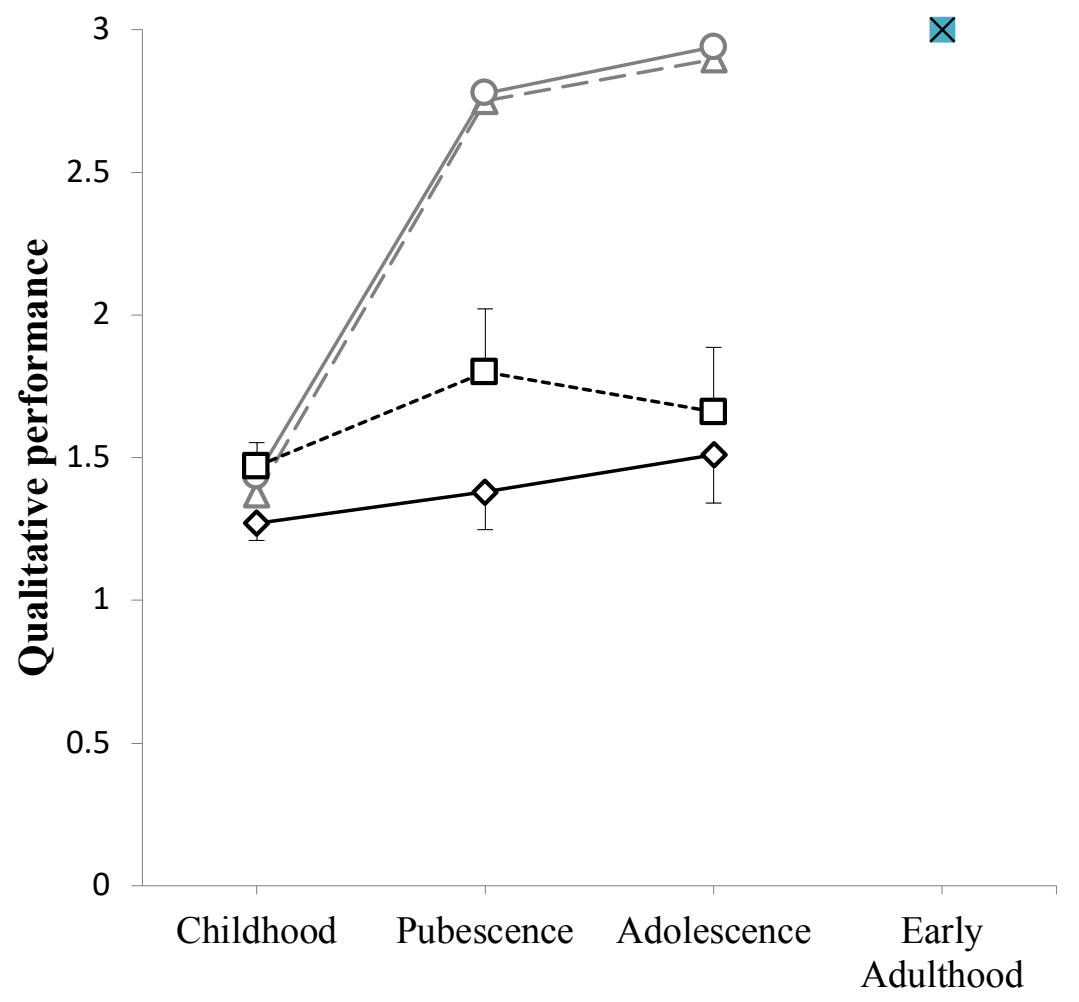

$-\triangle-$ female athletes

- - - male athletes

$\checkmark$ female novices

-- $\square$-- male novices

$x$ reference group

Level of development in motor ontogenese

Figure 6 Changes of the qualitative performance for forearm action ( $\min .0$ - max. 3 ) for male and female athletes (Gromeier et al., 2017) and male and female novices as a function of age (childhood, pubescence, adolescence, and early adulthood). The qualitative performance was in a range of .0 to 3.0 and was calculated as the mean of three independent expert ratings (cf. method section). Standard deviation marked by the error bars.

Figure 6 shows changes in the quality of forearm action. There is no significant effect of age on the qualitative performance of forearm action, $F(2,104)=2.102, p=.127$. The analysis yielded a significant effect of gender on the qualitative performance of forearm action, $F(1,104)=4.518$, $p=.036$. As with consideration of the humerus action, the interaction between age and gender on the quality of forearm action was not significant, $F(2,104)=.368, p=.693$. 


\section{Changes in the movement of stepping}

Qualitative characteristics in stepping action

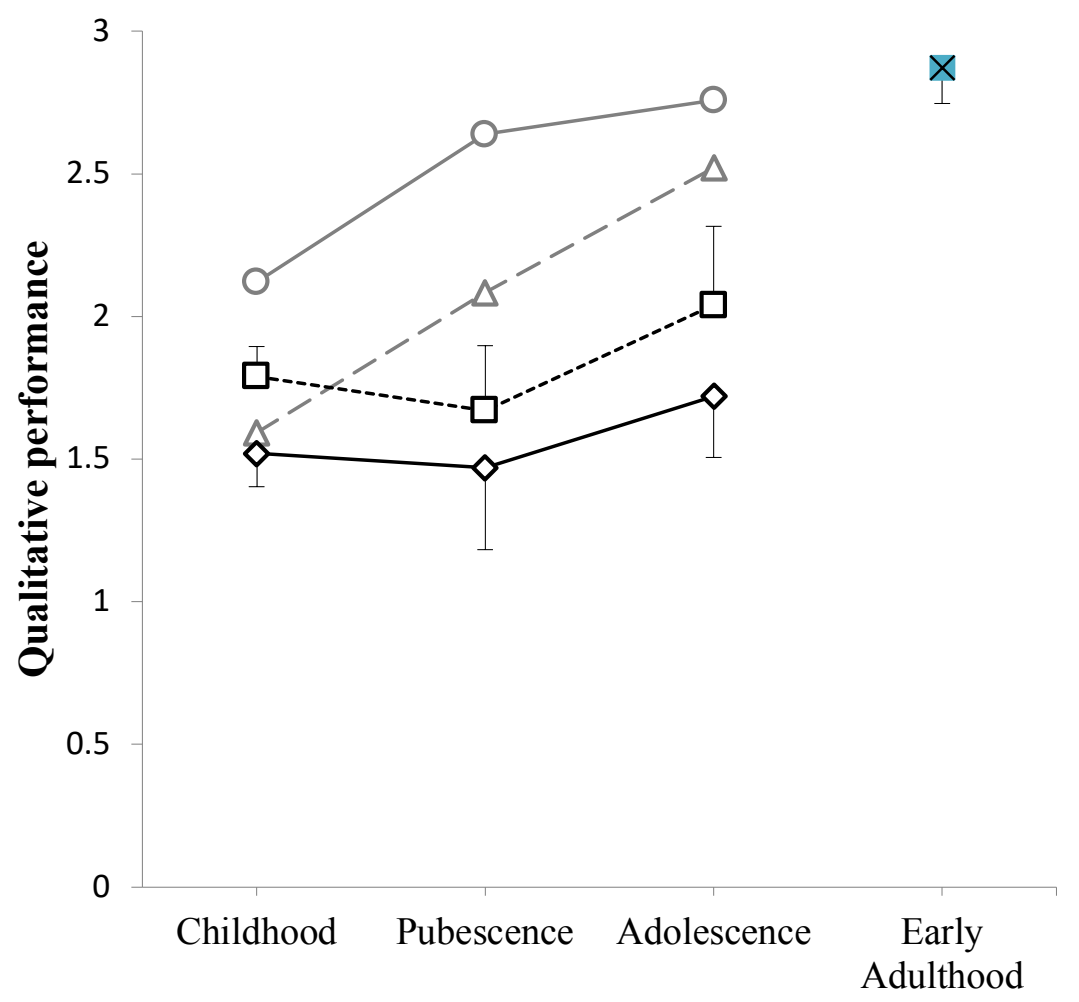

$-\triangle-$ female athletes

- - male athletes

$\diamond$ female novices

-- $\square$--- male novices

$x$ reference group

Level of development in motor ontogenese

Figure 7 Changes of the qualitative performance for stepping action ( $\min .0$ - max. 3 ) for male and female athletes (Gromeier et al., 2017) and male and female novices as a function of age (childhood, pubescence, adolescence, and early adulthood). The qualitative performance was in a range of .0 to 3.0 and was calculated as the mean of three independent expert ratings (cf. method section). Standard deviation marked by the error bars.

The changes in the qualitative performance of stepping for male novices and female novices are visualized in Figure 7. The ANOVA yielded no significant effect of age, $F(2,104)=.983, p=$ .348. The analysis showed no significant effect of gender on qualitative performance of stepping, $F(1,104)=2.363, p=.127$. An interaction effect of age and gender was significant, $F(2,104)=.037, p=.037$. 


\section{Changes in the movement of backswing}

Qualitative characteristics in backswing action

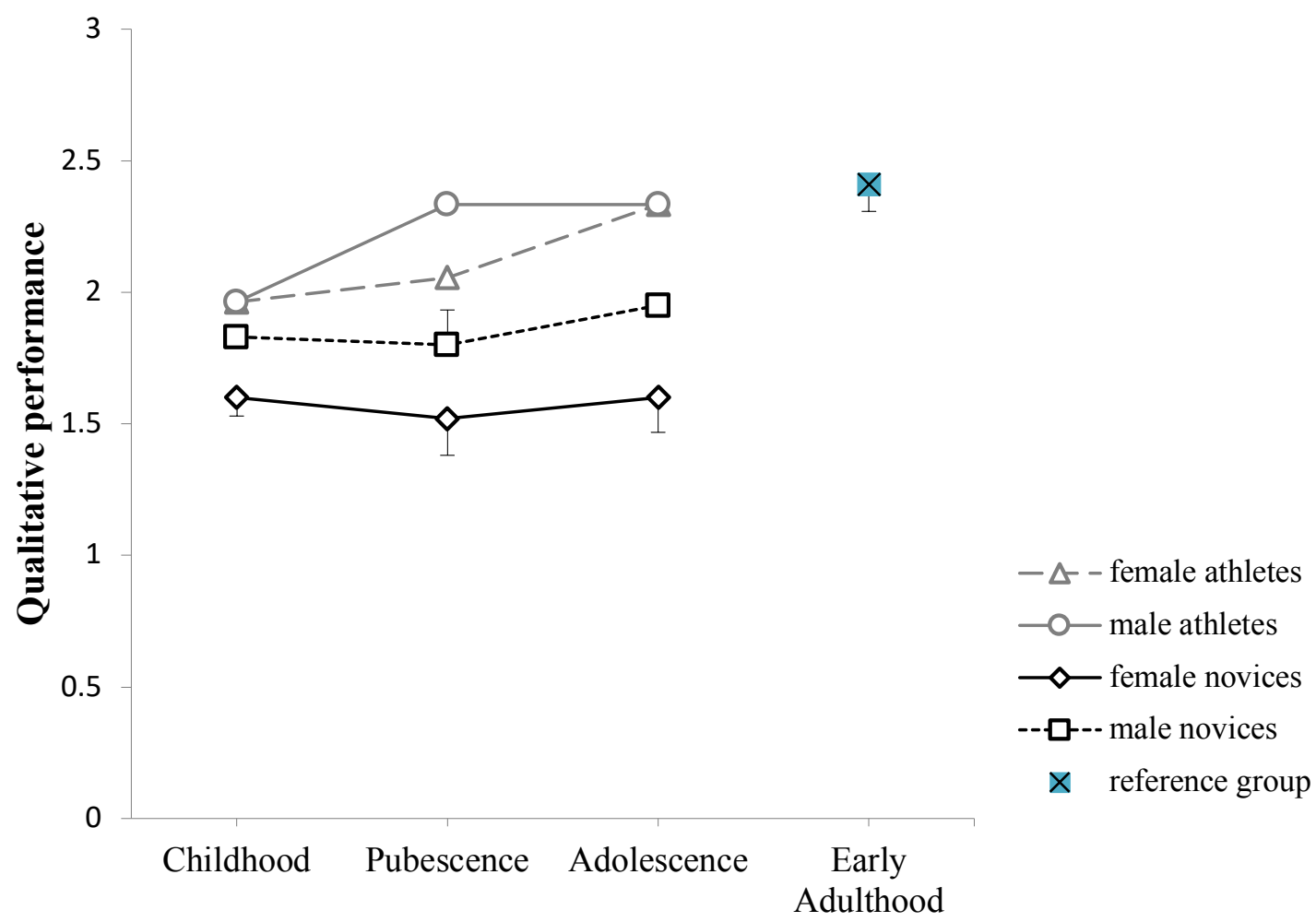

Level of development in motor ontogenese

Figure 8 Changes of the qualitative performance for backswing action (min. 0 - max. 3) for male and female athletes (Gromeier et al., 2017) and male and female novices as a function of age (childhood, pubescence, adolescence, and early adulthood). The qualitative performance was in a range of .0 to 3.0 and was calculated as the mean of three independent expert ratings (cf. method section). Standard deviation marked by the error bars.

The changes in the qualitative performance of backswing are highlighted in Figure 8. Using the ANOVA the analysis showed no significant effect of age on quality of the backswing, $F(2,104)=$ $.444, p=.643$. The analysis showed a significant effect of gender, $F(1,104)=10.519, p=.002$. An interaction effect of age and gender was not significant, $F(2,104)=.190, p=.827$.

Table 3

T-tests for independent samples showed effects of gender on five components (trunk, humerus, forearm, stepping, and backswing) for novices according to levels of development in the motor ontogenesis (childhood, pubescence, and adolescence). Significant comparisons are highlighted here and in all subsequent tables.

\begin{tabular}{|c|c|c|c|c|c|c|}
\hline \multirow{2}{*}{ Component } & \multicolumn{2}{|c|}{$t(\mathrm{df})$} & \multicolumn{2}{|c|}{$t(\mathrm{df})$} & \multicolumn{2}{|c|}{$t(\mathrm{df})$} \\
\hline & \multicolumn{2}{|c|}{ Childhood } & \multicolumn{2}{|c|}{ Pubescence } & \multicolumn{2}{|c|}{ Adolescence } \\
\hline 1) Trunk & -5.643 & $p<.001$ & -4.985 & $p<.001$ & -1.500 & $p=.153$ \\
\hline 2) Humerus & -1.794 & $p=.077$ & -.365 & $p=.720$ & -.814 & $p=.427$ \\
\hline 3) Forearm & -1.995 & $p=.050$ & -1.607 & $p=.130$ & -.539 & $p=.597$ \\
\hline 4) Stepping & -1.694 & $p=.094$ & -.523 & $p=.609$ & -.921 & $p=.371$ \\
\hline 5) Backswing & -2.726 & $p=.008$ & -1.385 & $p=.186$ & -2.444 & $p=.030$ \\
\hline Qualitative Performance & -3.938 & $p<.001$ & -1.981 & $p=.066$ & -1.650 & $p=.119$ \\
\hline $\begin{array}{l}\text { Quantitative } \\
\text { Performance }\end{array}$ & -3.996 & $p<.001$ & -.912 & $p=.376$ & -.810 & $p=.430$ \\
\hline
\end{tabular}


Using $T$-test for independent samples,effects of gender in the qualitative performance for all components, total qualitative performance, and the quantitative performance were analyzed and highlighted in Table 3.Throughout the different age bands (childhood, pubescence, and adolescence) only few gender differences in the development of qualitative and quantitative performance throwing were demonstrated (greyed background). Within childhood there are significant gender differences in quantitative performance $(p<.001)$ and qualitative performance $(p<.001)$ in favour of male novices. With a closer look, differences in the qualitative performance were found in trunk $(p<.001)$, forearm $(p=.050)$, and backswing actions $(p=.008)$. The significant differences in trunk action $(p<.001)$ continue to exist in the pubescence. Within the adolescence significant gender differences in favour of male were found for backswing action $(p=.030)$. Furthermore, no gender differences can be recognized throughout the three age bands. Thus, the throwing movement developed for the most components and the throwing performances in the same manner. To highlight possible effects of age of qualitative performance of all movement components, total qualitative performance, and quantitative performance within male and female novices T-tests for independent samples was used (see Table 4 and Table 5). In addition, the performances of adolescence with the performances of the reference group in the early adulthood were compared.

Table 4

T-tests for independent samples showed effects of age (childhood to pubescence, childhood to adolescence, pubescence to adolescence, and adolescence to early adulthood) on five components (trunk, humerus, forearm, stepping, and backswing), total qualitative performance, and quantitative performance according to male novices and reference group.

$t(\mathrm{df})$

Component

\begin{tabular}{|c|c|c|c|c|c|c|c|c|}
\hline \multirow{2}{*}{ 1) Trunk } & \multicolumn{2}{|c|}{$\begin{array}{l}\text { Childhood - } \\
\text { Pubescence }\end{array}$} & \multicolumn{2}{|c|}{$\begin{array}{l}\text { Childhood - } \\
\text { Adolescence }\end{array}$} & \multicolumn{2}{|c|}{$\begin{array}{l}\text { Pubescence - } \\
\text { Adolescence }\end{array}$} & \multicolumn{2}{|c|}{$\begin{array}{l}\text { Adolescence - Early } \\
\text { Adulthood }\end{array}$} \\
\hline & -.025 & $p=.980$ & .366 & $p=.716$ & .331 & $p=.745$ & -4.313 & $p<.001$ \\
\hline 2) Humerus & -.598 & $p=.552$ & -1.239 & $p=.222$ & -.392 & $p=.700$ & -3.889 & $p<.002$ \\
\hline 3) Forearm & -1.598 & $p=.117$ & -.842 & $p=.404$ & .404 & $p=.692$ & -5.798 & $p<.001$ \\
\hline 4) Stepping & .537 & $p=.593$ & -.895 & $p=.376$ & -1.067 & $p=.303$ & -2.853 & $p=.014$ \\
\hline 5) Backswing & .333 & $p=.740$ & -1.750 & $p=.096$ & -1.076 & $p=.305$ & -4.044 & $p=.002$ \\
\hline $\begin{array}{l}\text { Qualitative } \\
\text { Performance }\end{array}$ & -.413 & $p=.681$ & -1.098 & $p=.278$ & -.486 & $p=.634$ & -10.054 & $p<.001$ \\
\hline $\begin{array}{l}\text { Quantitative } \\
\text { Performance }\end{array}$ & -.162 & $p=.872$ & -.283 & $p=.778$ & -.104 & $p=.916$ & -4.237 & $p=.004$ \\
\hline
\end{tabular}

Table 5

T-tests for independent samples showed effects of age (childhood to pubescence, childhood to adolescence, pubescence to adolescence, and adolescence to early adulthood) on five components (trunk, humerus, forearm, stepping, and backswing), total qualitative performance, and quantitative performance according to female novices and reference group.

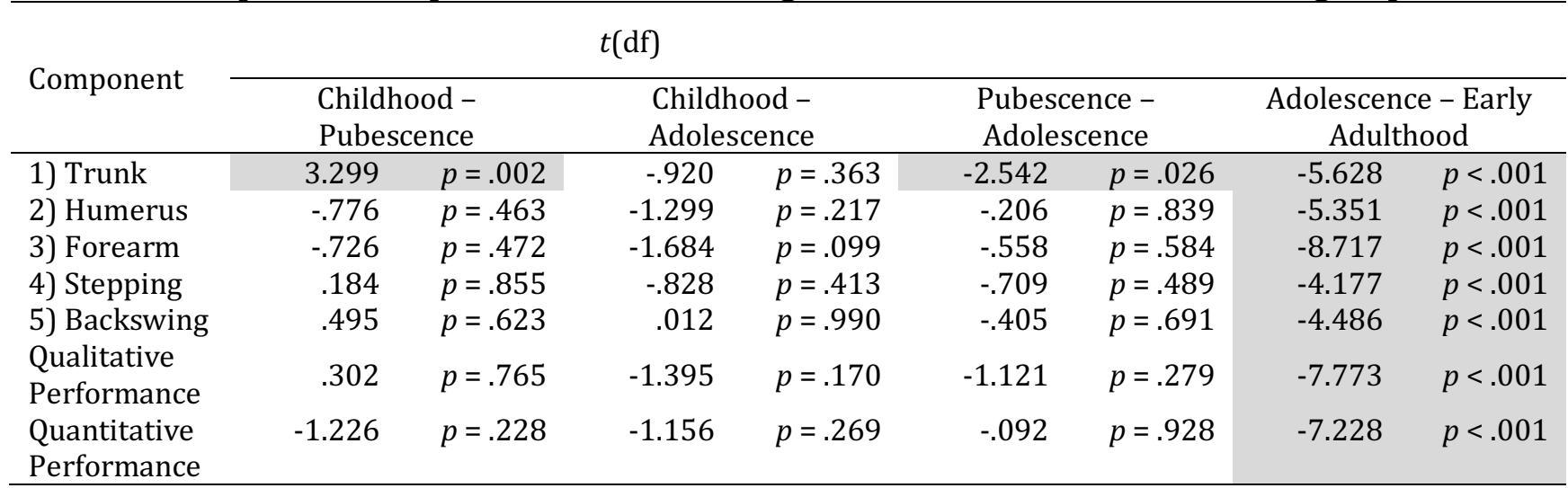


Table 4 and 5 highlights effects of age within male and female novices. Only few effects of age (grayed background) can be seen in the development of female novices. These differences are located in the trunk action between childhood and pubescence, and pubescence and adolescence. Within male novices no effects of age are visible. Furthermore, within male and female novices between childhood and adolescence no significant differences can be seen. It is remarkable that there are no differences between the various levels of development in motor ontogenesis. Thus, no improvement of the throwing movement can be recognized and the development stagnates on the level of childhood. If the performance of male and female novices in the adolescence is compared with the performances from the reference group in the early adulthood, clearly differences were found. There are significant effects of age in the qualitative performances of all component actions (trunk, humerus, forearm, stepping, and backswing) and quantitative performance between the adolescence and the early adulthood.

\section{DISCUSSION}

This study investigated age and gender-related differences among novices during childhood, pubescence and adolescence. Across these age bands, hardly any improvement, in performance, neither in the quality of the throwing movement nor in the throwing accuracy was found. The analysis of the separate movement components (Halverson \& Roberton, 1984) yielded a more differentiated picture. To identify major problems in the course of development within novices, different components of movement were analyzed according to the component approach (Halverson \& Roberton, 1984). Following questions should be answered: What are the main problems in the development of the throwing movement within children and youth novices? Where are the differences in the qualitative performance of the throwing movements within male and female novices situated? And last question: How does physical education foster skill acquisition in novices during childhood and adolescence compared to athletes of sport clubs in the same age range? Therefore, the focus was on the five essential component actions. Regarding the influence of age, it is hypothesized that quantitative and qualitative throwing performances develop with increasing age. Furthermore, it was hypothesized that from late childhood these performances differ between male and female novices in favour of males, and these differences widen of with increasing age (Meinel \& Schnabel, 1998, S. 288).

From six to 16 years of age male and female novices differ significantly in the trunk action. They did not develop their skills, that is, their performance stagnated on the childhood level. Male novices demonstrated a block rotation, whereas female novices demonstrate no trunk action but a forward-flexion in trunk action. This confirms the statements of Goodway and Lorson (2008), Halverson et al. (1982), and Lorson et al. (2013) which highlighted a slower development in trunk action of female novices.

The male and female novices stagnate in the throwing behavior of humerus action until the aged of 16 years and in contrast to Lorson et al. (2013) and Goodway and Lorson (2008), male and female novices show the same moving pattern. The upper arm movement is constantly below shoulder level and the elbow is only tendentially directed forward.

The forearm action differs on a low level of performance between male and female novices. These results confirm studies of Lorson et al. (2013) and Goodway and Lorson (2008) who found gender specific differences in the forearm action.

In contrast with results of Lorson et al. (2013) and Goodway and Lorson (2008) male and female novices show no significant difference in stepping action. Minor differences in the moving pattern can be recognized. Thus, female novices were characterized by no stepping 
action or an ipsilateral stepping action, whereas male novices mostly showed an ipsilateral stepping or a contralateral long step.

Female novices showed distinct problems in the backswing action. They demonstrated a backswing behind or beside the head with nearly no backward extension. Male novices showed marginal development in the backswing and demonstrated a backswing behind or beside the head with an insufficient backward extension.

Regarding the main problems in the development of the throwing movement within children and youth novices, it is shown that both sexes had problems to perform a correct throwing movement (qualitative characteristics). Specifically, all five components (trunk, humerus, forearm, stepping, and backswing actions) are equally affected. Although male and female novices differ slightly in trunk, forearm, and backswing actions, all five components are on a low or moderate level of development and differ significantly from those of handball athletes (Table 5) and the reference group; as could be expected athletes excelled novices.

Regarding the question, how does physical education foster skill acquisition in novices during childhood and adolescence compared to athletes of sport clubs in the same age range, the comparison of skill acquisition to athletes based on results of Gromeier et al. (2017) show that with increasing age, qualitative performance of male and female athletes improves. Furthermore it can be seen that male and female athletes demonstrated similar movement patterns in the main function phase, humerus and forearm actions, which is form the forearm whip and the most important component in the overarm throwing movement. Looking to the performance, we recognised that a specific and purposeful training intervention can apparently alter the throwing pattern of males and females and both lead to a proficient mover, which in turn speaks for a successful intervention. Such a development cannot be seen in the novices examined in the present study, which may call for additional effort in physical education to improve basic motor skills.

With a view to influences of single components on the quantitative throwing performance, it should be noted that the main functional phase of the overhead throwing movement is the forearm whip, which is composed of the humerus and forearm actions. The main function phase is supposed to be functionally independent, and it should be directly connected to the movement task with no relation to other phases (Göhner, 1979). Therefore, the humerus and forearm action represents the core of a movement. A correct execution of the forearm whip is essential for the achievement of task goals, which in our case was throwing as hard and accurate as you can. It is important that the elbow is not dropping below shoulder level, and the throwing hand is pulled forward close to the head. If there are mistakes in these movement characteristics, it is very difficult to achieve the tasks. It was already noted that male and female novices stagnate on a low level of qualitative performance in humerus and forearm action. Consistently, the quantitative performance of male and female novices also appears to stagnate on low level. The results clearly suggest that, it is hardly possible for novices to achieve higher scores in throwing accuracy without improving components of the overhead throwing movement. This seems to be possible for trained children and young people in the same age range (Gromeier et al., 2017).

Contrary to the assumptions the qualitative performances of the throwing movements between male and female novices differ only in some movement components. Mostly no differences in the throwing movement can be observed for the isolated movement components and the gap between male and female did not increase as reported by Halverson et al. (1982) reported. Thus for most components the hypothesis that the qualitative performances of the 
overhead throwing movement differs between male and female novices has to be rejected. Despite the described differences in movement pattern, both genders stagnate at a low level of qualitative and quantitative performances. These findings stand as opposed to results of Halverson et al. (1982), Roberton and Langendorfer (1980), Roberton and Konczak (2001), and Gooway and Lorson (2006), who found gender related differences in different ages in favour of male.

Contrary to Meinel and Schnabel (1998) and Goodway and Lorson (2008), within the novices the motor skills did not improve due to the physical education. Therefore, the hypothesis that novices improve in qualitative and quantitative performances with increasing age must be rejected. For physical education and university education it is important to mention that the development of the throwing movement has probably not been completed with reaching adolescence. Possible previous experience of schoolchildren and physical education students cannot be presupposed. Therefore, the practice in complex motor skills should continue after school education. With view to the learning process of fundamental qualitative skills for sports like handball or warm up games and of qualitative skills for learning the process of the ball- or javelin-throw, school and university education should address these problems within novices. To enhance the development opportunities of novices, physical education should support a wide development addressing all essential components of the throwing movement. Furthermore, other tools for improvement may be required, if increasing practise time is not a practical option.

Halverson et al. (1982) suggest that gender differences were the result of the greater practice time of boys. Williams, Haywood, and Painter (1996) confirm this assumption. They analyzed age and gender differences in ball velocity and throwing pattern for dominant and non dominant arms. Overall, they found marginal gender differences for velocity and throwing pattern. Movement pattern of the non dominant arm exhibited the patterns of an unpractised performer (i.e., novices). These results demonstrate the necessity of specific practices in physical education. Because gender seems to be an insignificant, marginal predictor of throwing behaviour, instructions should not focus on gender stereotypes and prejudices but rather take an educational stance, including precise explanations about movement components, more practise time, and the development of new teaching techniques.

\section{CONCLUSION}

The purpose if this cross-sectional study was to examine the development of throwing movement skill within male and female novices and to highlight differences in the qualitative performance and quantitative performance. It is been shown that across a lifespan six to 16 years (in three age bands) male and female novices stagnated on a low level of movement development regarding the throwing skill. This contrasts with handball athletes of the same age range (Gromeier et al., 2017). In addition, novices differ in a few qualitative performances but not all movement components are affected similarly. Within the childhood, gender differences in favour of male were demonstrated for trunk, forearm, backswing actions, and quantitative performance. Within the pubescence, gender differences were demonstrated for trunk action and within the adolescence for backswing action. It is remarkable for physical education and university education that there seems to be no age-related developments in throwing movement of novices, especially in humerus and forearm action, and thus no improvement in quantitative performance. Regarding the main results of present study, important questions about content and methods of physical education are raised: Are the teaching methods suitable for all male and female students? What are possible deficits in learning process of throwing movements? 


\section{References}

Ahnert, J. (2005). Motorische Entwicklung vom Vorschul- bis ins frühe Erwachsenenalter: Ein-flussfaktoren und Prognostizierbarkeit. München: Verlag Deutsches Jugendinstitut.

Barrett, D. D. \& Burton, A. W. (2002). Throwing Patterns Used by Collegiate Baseball Players in Actual Games. Research Quarterly for Exercise and Sport, 73 (1), 19-27.

Ehl, T., Langendorfer, S. J., \& Roberton, M.A. (2005). Does the throwing "Gender gap" occur in Germany? Research Quarterly for Exercise and Sport, 76 (4),488-493.

Gaschler, P. (1998). Motorische Entwicklung und Leistungsfähigkeit von Vorschulkindern in Abhängigkeit von Alter und Geschlecht. Chemie in unserer Zeit, 18 (4), 5-18.

Geese, R. (1997). Geschlechtsspezifische Unterschiede in der Wurfmotorik. Spectrum der Sportwissenschaften. Zeitschrift der österreichischen sportwissenschaftlichen Gesellschaft, 9 (2), 31-42.

Göhner, U. (1979). Bewegungsanalyse im Sport. Schorndorf: Hofmann.

Goodway, J. D., \& Lorson, K. M. (2008). Gender differences in throwing form of children ages 6-8 years during a throwing game. Research Quarterly for Exercise and Sport, 79 (2),174-182.

Gromeier, M., Koester, D., \& Schack, T. (2017). Developmental gender-specific differences in motor skills of the overarm throw. Frontiers Psychology and Sport Science.

Halverson, L. E., Roberton, M. A., \& Langendorfer, S. (1982). Development of the Overarm Throw: Movement and Ball Velocity Changes by Seventh Grade. Research Quarterly for Exercise and Sport, 53, 3, 198-205.

Halverson, L. E., \& Roberton, M. A., (1984). Developing children - their changing movement: a guide for teachers. Philadelphia: Lea \& Febiger.

Hamilton, M. L., \& Tate, A. L. (2002). Constraints on throwing behavior: An exploratory analysis. In J. E. Clark (Eds.), Advances in motor development research (Vol. 2, pp. 49-61). American Alliance for Health, Physical Education, Recreation, and Dance: Reston, VA: NASPE Publications.

Keogh, J. F. (1969). Change in motor performance during early school years. Los Angeles: Department of Physical Education, University of California.

Langendorfer, S. J. \& Roberton, M.A. (2002).Individual pathways in the development of forceful throwing. Research Quarterly for Exercise and Sport, 73(3), 245-256.

Lorson, K. M. (2003). The influence of three instructional strategies on the performance of the overarm throw. (Doctoral dissertation, Ohio State University. Retrieved from https://etd.ohiolink.edu/rws_etd/document/get/osu1060881637/inline

Lorson, K. M., Stodden, D. F., Langendorfer, S. J., \& Goodway, J. D. (2013) Age and Gender Differences in Adolescent and Adult Overarm Throwing. Research quarterly for exercise and sport, 84, 239-244.

Meinel, K., \&Schnabel, G. (1998).Bewegungslehre - Sportmotorik: Abriß einer Theorie der sportlichen Motorik unter pädagogischem Aspekt, Berlin: Sportverlag.

Morris, A., Williams, J., Atwater, A., \& Wilmore, J. (1982). Age and Sex Differences in Motor Performance of 3 Through 6 Year Old Children. Research Quarterly for Exercise and Sport, 53, 3, 214-221.

Nelson, R. N., Thomas, J. R., \& Nelson, J. K. (1991). Longitudinal change in throwing performance. Research Quarterly for Exercise and Sport, 62, 105-108.

Roberton, M. A., \& Konczak, J. (2001). Predicting children's overarm throw ball velocities from their developmental levels in throwing. Research quarterly for exercise and sport, 72 (2), 91-103.

Schack, T.; \& Bar-Eli, M. (2007). Psychological factors in technical preparation. In B. Blu-menstein \& R. Lidor (Eds.), Psychology of sport training (pp. 62-103). Münster: Meyer \& Meyer.

Thomas, J. R., \& French, K. E. (1985).Gender Differences across age in motor performance - A meta-analysis. Psychological Bulletin, 98 (2), 269-282.

Thomas, J. R., Michael, D., \& Gallagher, J. D. (1994). Effects of training on gender differences in overhand throwing: A brief quantitative literature review. Research Quarterly for Exercise and Sport, 65, 67-7 1

Vogt, U. (1978). Die Motorik 3- bis 6-jähriger Kinder. Ihre Abhängigkeit vom biologischen Entwicklungsstand und sozialen Umweltfaktoren, Beiträge zur Lehre und Forschung im Sport. Schorndorf: Hofmann. 
Winter, R. (1987). Die motorische Entwicklung des Menschen von der Geburt bis ins hohe Alter (Überblick). In K. Meinel \& G. Schnabel (Hrsg.), Bewegungslehre - Sportmotorik (S. 275-397). Berlin: Sportverlag.

Williams, K., Haywood, K., \& Painter, M. (1996). Environmental versus Biological Influences on Gender Differences in the Overarm Throw for Force: Dominant and Nondominant Arm Throws. Women in Sport and Physical Activity Journal, 5, $29-48$.

World Medical Association. World Medical Association Declaration of Helsinki Ethical Principles for Medical Research Involving Human Subjects. The Journal of the American Medical Association. 2013; 310: 2191-2194.

Figure Caption

Figure 9 Drawing of the test setup of motor skills examination from bird's-eye view. (n=body height, Target Size (a) $75 \mathrm{~cm} \times 75 \mathrm{~cm}$ in shoulder height (h), camera in 90 degree angles in a distance of $5 \mathrm{~m}$ to the participant).

Figure 10 Changes of the qualitative performance for all components (min. 0 - max. 3) for male and female athletes and male and female novices as a function of age (childhood, pubescence, adolescence, and early adulthood). The qualitative performance was in a range of .0 to 3.0 and was calculated as the mean of three independent expert ratings (cf. method section).Standard deviation marked by the error bars.

Figure 11 Changes of the quantitative performance for all components (min. 0 - max. 3) for male and female athletes and male and female novices as a function of age (childhood, pubescence, adolescence, and early adulthood). The quantitative performance was calculated by hits on target or which touched the mark of the target (cf. method section). Standard deviation marked by the error bars.

Figure 12 Changes of the qualitative performance for trunk action (min. 0 - max. 3) for male and female athletes and male and female novices as a function of age (childhood, pubescence, adolescence, and early adulthood). The qualitative performance was in a range of .0 to 3.0 and was calculated as the mean of three independent expert ratings (cf. method section).Standard deviation marked by the error bars.

Figure 13 Changes of the qualitative performance for humerus action (min. 0 - max. 3) for male and female athletes and male and female novices as a function of age (childhood, pubescence, adolescence, and early adulthood). The qualitative performance was in a range of .0 to 3.0 and was calculated as the mean of three independent expert ratings (cf. method section).Standard deviation marked by the error bars.

Figure 6 Changes of the qualitative performance for forearm action (min. 0 - max. 3) for male and female athletes and male and female novices as a function of age (childhood, pubescence, adolescence, and early adulthood). The qualitative performance was in a range of .0 to 3.0 and was calculated as the mean of three independent expert ratings (cf. method section).Standard deviation marked by the error bars.

Figure 7 Changes of the qualitative performance for stepping action (min. 0 - max. 3) for male and female athletes and male and female novices as a function of age (childhood, pubescence, adolescence, and early adulthood). The qualitative performance was in a range of .0 to 3.0 and was calculated as the mean of three independent expert ratings (cf. method section).Standard deviation marked by the error bars.

Figure 8 Changes of the qualitative performance for backswing action (min. 0 - max. 3) for male and female athletes and male and female novices as a function of age (childhood, pubescence, adolescence, and early adulthood). The qualitative performance was in a range of .0 to 3.0 and was calculated as the mean of three independent expert ratings (cf. method section).Standard deviation marked by the error bars. 